\title{
Calculation methodology for determining the number of simultaneous self-starting pumping units
}

\author{
K.G. Abidov ${ }^{1, *}$, O.O. Zaripov ${ }^{1}$, A.I. Rakhmatullaev ${ }^{1}$, N.O. Zaripov ${ }^{1}$, Sh.O. Zaripova ${ }^{2}$ \\ ${ }^{1}$ Tashkent State Technical University named after Islam Karimov University street №2, Tashkent city; Uzbekistan \\ ${ }^{2}$ Karshi Institute of Engineering and Economics
}

\begin{abstract}
The paper considers the methodology of calculating the number of self-starting pump units depending on the network voltage landing and the basic calculation dependencies of the process of selfstarting of electric motors supplied from three-phase three-winding transformer; the substitution scheme for one phase of the circuit is made. Technical solutions for upgrading pump units, which allow applying the selfstart mode at ameliorative pumping stations, are proposed.
\end{abstract}

\begin{abstract}
Keywords. Self-start, transient, reclamation pumping stations, pump unit, electrical equipment, starts, emergency shutdowns, pipeline, free-running, shutdown, power equipment, electric drive, induction motor, power system, power line, self-start device.
\end{abstract}

\section{Introduction}

One of the main factors influencing the yield of agricultural crops, in particular cotton, is timely irrigation. Therefore, uninterrupted operation of pumping units during the irrigation season to ensure the specified water delivery schedule of pumping stations is of great importance for the economy of the republic.

During planned shutdowns of pump units in pumping stations the gate valve in the discharge line is closed beforehand [1]. In this case the speed of the pump unit is reduced to zero. In addition, water remains in the discharge line (manifold). At present, both in case of an emergency as well as in case of a successful automatic reclosure (reclosure) of the power grid there is a complete abrupt shutdown of the pump units of the pumping stations. Due to the loss of drive by the pump, the flow is reduced to zero and the unit will rotate in the same direction. The water flow through the pump initially slows the pump down, the speed reaches zero, then the direction of rotation changes to turbine mode and accelerates to a steady angular speed, as the pipeline is emptied it slows down and stops. As a consequence, no water remains in the manifold, the pump glands burn and fail, fasteners are loosened and the entire pump unit fails [2].

Pump plugs must be removed, damaged glands removed, new gland packings stuffed and plugs reassembled in order to start the pump unit after repainting. The rear gate valve must be closed tightly to create a vacuum before the pump is started. Therefore, in such cases it is necessary to fill the manifold with water in order to create a vacuum in the pump before start-up. An emergency situation is created at the pumping station after each repowering. Start-up of pumping units requires qualified personnel and scarce materials (gland packing, turbine oil). It takes a long time (2-3 days) to carry out start-up and bring the pumping unit to its normal operating condition, which leads to disruption of water supply for irrigation. Therefore, the problem of selfstarting of pumping units is urgent [3].

\section{Methods}

The number of pump units installed in reclamation pumping stations varies widely (2-16). The drive motors of the pumps are supplied by the step-down substation of the pump station. Two-winding and three-winding transformers are used in these substations.

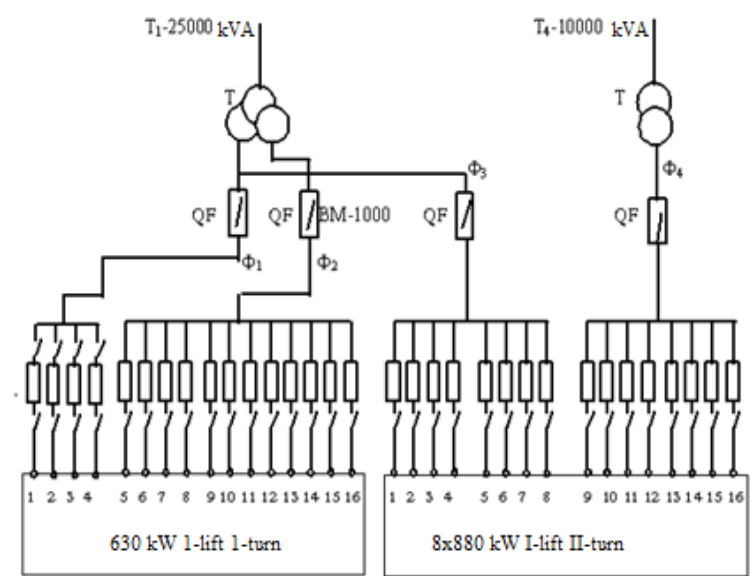

Fig. 1. Electrical scheme of the Amu-Zang-I, I and II stage pumping station

\footnotetext{
* Corresponding author: abidoff@rambler.ru
} 
The number of simultaneous self-starting motors in a pumping station is determined on the basis of the permissible mains voltage drop at the time of self-starting. Knowing the mains voltage and the power supply resistance, the value that restores the voltage to the motors is determined. If the torque of the motor at this voltage is greater than the pumps' resistance torque, the motor can be restarted.

A calculation procedure for determining the number of self-starting pumping units depending on the mains voltage landing is given. Fig. 1 shows the power supply scheme of typical pumping stations of the first lift. The main calculated dependencies of the self-starting process of electric motors supplied from a 3-phase three-winding transformer are derived.

Primary rated line voltage: $\mathrm{U}_{\mathrm{vl}}$

Primary phase voltage:

$U_{1 p v}=\frac{U_{v l \pi}}{\sqrt{3}} ; \quad U_{2 p v}=U_{2 v l}$

Transformer transformation ratio:

$\mathrm{K}_{t_{12}}=\mathrm{K}_{t_{13}}=\frac{U_{1 p v}}{U_{2 p v}}=\frac{U_{1 p v}}{U_{3 p v}} ;$

Determine the rated winding currents of the three-winding transformer:

$$
\begin{aligned}
& I_{1_{p v}}=I_{1 v l}=\frac{S_{v I} \cdot 10^{3}}{\sqrt{3} \cdot U_{1_{v l}}} ; \\
& I_{2_{\text {нл }}}=I_{3_{\text {нл }}}=\frac{S_{v I I} \cdot 10^{3}}{\sqrt{3} \cdot U_{2_{v l}}}=\frac{S_{v I I} \cdot 10^{3}}{\sqrt{3} \cdot U_{3 v l}} ; \\
& I_{2_{p v}}=I_{3_{p v}}=\frac{I_{2 n l}}{\sqrt{3}}=\frac{I_{3 n l}}{\sqrt{3}}
\end{aligned}
$$

From the short-circuit voltage values, find the total shortcircuit resistance relating to one phase when the supply transformer is three-winding:

$$
\begin{gathered}
Z_{\mathrm{K}_{23}}=\frac{U_{\mathrm{K}_{23}}}{100} \cdot \frac{U_{1 p v}}{I_{1_{p} v}} ; \\
Z_{\mathrm{K}_{12}}=\frac{U_{\mathrm{K}_{12}}}{100} \cdot \frac{U_{1_{p v}}}{I_{1_{p v}}} ; \\
Z_{\mathrm{K}_{13}}=\frac{U_{\mathrm{K}_{13}}}{100} \cdot \frac{U_{1_{p v}}}{I_{1_{p v}}}
\end{gathered}
$$

Bring these resistances to the secondary and tertiary windings:

$$
\begin{aligned}
& Z_{\kappa_{23}}^{\prime}=Z_{\kappa_{23}} \cdot \frac{1}{K_{m}^{2}} ; \\
& Z_{\kappa_{12}}^{\prime}=Z_{\kappa_{12}} \cdot \frac{1}{K_{m}^{2}} \\
& Z_{\kappa_{13}}^{\prime}=Z_{\kappa_{13}} \cdot \frac{1}{K_{m}^{2}} .
\end{aligned}
$$

Ignore the active components of the short-circuit resistances. Then the inductive short-circuit resistances reduced to the secondary and tertiary windings:

$$
X_{\kappa_{23}}^{\prime} ; \quad X_{\kappa_{12}}^{\prime} ; \quad X_{\kappa_{13}}^{\prime} \text {. }
$$

Inductive resistance of the primary winding dissipation reduced to the secondary and tertiary windings:

$$
X_{\delta_{1}}^{\prime}=\frac{X_{\kappa_{12}}^{\prime}+X_{\kappa_{13}}^{\prime}+X_{\kappa_{23}}^{\prime}}{2} ;
$$

Inductive resistance of the secondary and tertiary windings:

$$
\begin{aligned}
& X_{\delta_{2}}^{\prime}=\frac{X_{\kappa_{12}}^{\prime}+X_{\kappa_{23}}^{\prime}+X_{\kappa_{13}}^{\prime}}{2} ; \\
& X_{\delta_{3}}^{\prime}=\frac{X_{\kappa_{13}}^{\prime}+X_{\kappa_{23}}^{\prime}+X_{\kappa_{12}}^{\prime}}{2} .
\end{aligned}
$$

Convert the secondary and tertiary windings of a deltaconnected transformer to equivalent stars:

$$
\begin{aligned}
& X_{\delta_{13}}^{\prime}=\frac{X_{\delta_{1}}^{\prime}}{3} ; \\
& X_{\delta_{23}}^{\prime}=\frac{X_{\delta_{2}}^{\prime}}{3} ; \\
& X_{\delta_{33}^{\prime}}^{\prime}=\frac{X_{\delta_{3}}^{\prime}}{3} .
\end{aligned}
$$

Assum $\approx$ that the network supplying the transformer has infinite capacity. To calculate the self-start of the transformer-fed motors, make a substitution diagram (Fig. 2 ) for one phase of the circuit. Ignore the transmission line resistances.

The calculation formulas for the substitution diagram and self-starting of electric motors from a 3-winding transformer are given below:

On the basis of the obtained expressions a calculation is made at parametrically given motor slip values $\mathrm{S}=1$; 0,$5 ; 0,06$; current values in individual feeders $\mathrm{F}_{1} ; \mathrm{F}_{2} ; \mathrm{F}_{3}$; and voltage at the end of these feeders, i.e. at the terminals of individual groups of electric motors fed from these feeders and the voltage landing in the transformer windings (without considering the loss in the connecting cables), when the number of electric motors starting at $\mathrm{S}=1$ and self-starting at $\mathrm{S}=0,5 ; 0,06$ varies from one to four. Based on the calculated dependencies obtained, the number of self-starting electric motors of the operating pumping stations "Amu-Zang -I" is determined.

$$
\begin{array}{r}
Z_{f_{I}}=\left(\frac{R_{1_{I}}}{n_{1}}+\frac{R_{2_{I I}}^{\prime}}{n_{1} S}\right)+j \frac{X_{\mathrm{K}_{I}}}{n_{1}} ; \\
Z_{f_{I I}}=\left(\frac{R_{1_{I I}}}{n_{2}}+\frac{R_{2_{I I}}^{\prime}}{n_{2} S}\right)+j \frac{X_{\mathrm{K}_{I I}}}{n_{2}} ;
\end{array}
$$




$$
\begin{gathered}
Z_{f_{I I I}}=\left(\frac{R_{1_{I I I}}}{n_{3}}+\frac{R_{2_{I I I}}^{\prime}}{n_{3} S}\right)+j \frac{X_{\mathrm{K}_{I I I}}}{n_{3}}+j X_{\delta_{3 \ni}} ; \\
Z_{f_{I}}-F_{I I}=j X_{\delta_{2 \ni}}+\frac{Z_{f} \cdot Z_{f_{I I}}}{Z_{f_{I}}+Z_{f_{I I}}} ; \\
Z_{e}=j X_{\delta_{2 e}}^{\prime}+\frac{Z_{f_{I I I}} Z_{f_{I}}-\Phi_{I I}}{Z_{f_{I I I}}+Z_{f_{I}}-Z_{f_{I I}}} ; \\
I_{e}=\frac{U_{2 f}}{Z_{e}} ; \\
U_{f_{I I I}}=\frac{U_{\mathrm{AB}}}{Z_{F_{I I I}}} ; \quad I_{f}-U_{2 f}-I_{F_{I I I}} \cdot X_{\delta_{1 e}}^{\prime} \cdot \boldsymbol{I}_{e}-I_{f_{I I I}} ; \\
U_{q I I I}=\sqrt{3} I_{f_{I I I}}\left(\frac{R_{I I I}}{n_{3}}+\frac{R_{2 I I I}^{\prime}}{n_{3} S}+j \frac{X_{\mathrm{K} I I I}}{n_{3}}\right) ; \\
U_{q I_{l}}=U_{q I I l}=\sqrt{3}\left(U_{\mathrm{AB}}-U_{f_{I}}-I_{F_{I I}} \cdot X_{\delta_{23}}\right. \\
I_{f_{I}}=\frac{U_{q I I_{l}}}{\sqrt{3} Z_{f I}} ; \quad I_{f_{I I}}=\frac{U_{q I I l}}{\sqrt{3} Z_{f I I}}
\end{gathered}
$$

Parameters of transformer

TDTN-25000/110/6/6.

Scheme and winding connection group

$\mathrm{Y} / \Delta / \Delta /$-II-II.

Short circuit voltage:

$\mathrm{HV}-\mathrm{HV}$ at $2500 \mathrm{kVA} 10.7 \%$,

$\mathrm{HH}-\mathrm{HH}$ at $12500 \mathrm{kVA} 16.5 \%$,

$\mathrm{HV}-\mathrm{HV}$ at $12500 \mathrm{kVA} 9.87 \%$,

$\mathrm{HH}-\mathrm{HH}$ at $12500 \mathrm{kVA} 9.48 \%$.

3-phase asynchronous motor type

DAZO 15-59-10U1:

$\mathrm{U}_{\mathrm{dl}}=6 \mathrm{kV}, \eta=93 \%, \mathrm{P}_{2 \mathrm{H}}=630 \mathrm{kWt}$,

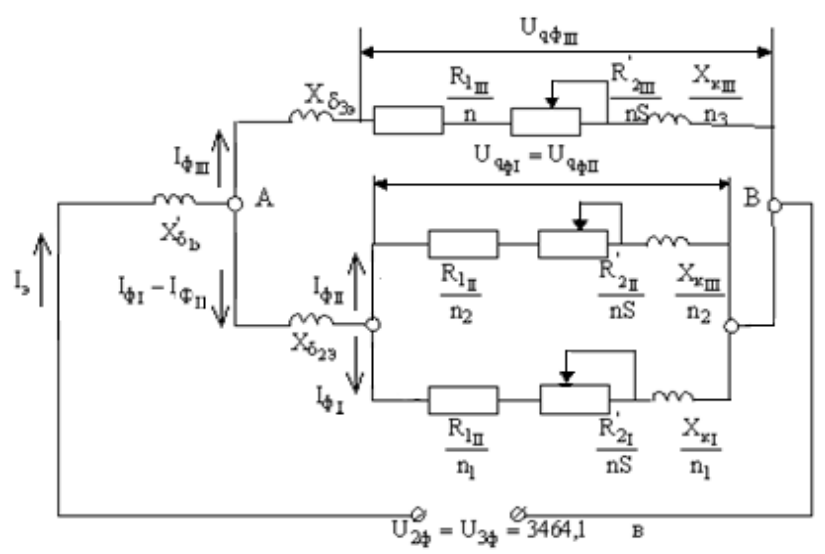

Fig. 2. Schematic diagram of one phase of a circuit supplied from a three-winding transformer

$$
\mathrm{M}_{\Pi_{k r}}=\frac{\mathrm{M}_{\Pi}}{\mathrm{M}_{\mathrm{H}}}=\mathbf{1}, \mathbf{3},
$$

$$
\begin{aligned}
& \mathrm{n}=595 \underset{I_{\Pi_{k r}}}{\operatorname{rpm},} \frac{\boldsymbol{I}_{\Pi}}{I_{\mathrm{H}}}=\mathbf{6 , 6}, \quad \mathrm{I}_{\mathrm{H}}=80 \mathrm{~A}, \\
& \mathrm{M}_{\text {maxkr }}=\frac{\mathrm{M}_{\mathrm{K}}}{\mathrm{M}_{\mathrm{H}}}=\mathbf{3}, \mathbf{2 6} ;
\end{aligned}
$$

Cos $\varphi_{\mathrm{n}}=0,81$. Pump type: 24 VAT, DRC $=875 \mathrm{~mm}$.

RESULTS. The results of the calculations are shown in summary table 1 and in figure 3. 3 .

Calculation of self-starting electric motors from TDTN25000/110/6/6 transformer.

Table 1

\begin{tabular}{|l|l|l|l|l|l|l|l|l|}
\hline $\mathrm{S}$ & $\mathrm{n}$ & $\begin{array}{l}\mathrm{U}_{\mathrm{qII}} \\
\mathrm{U}_{\mathrm{qIII}}\end{array}$ & $\mathrm{U}_{\mathrm{qIIII}}$ & $\mathrm{I}_{\mathrm{FI}}$ & $\mathrm{I}_{\mathrm{FII}}$ & $\mathrm{I}_{\mathrm{FIII}}$ & $\begin{array}{l}\Delta \mathrm{U}_{\mathrm{qII}}= \\
\Delta \mathrm{U}_{\mathrm{qIII}}\end{array}$ & $\Delta \mathrm{U}_{\mathrm{qIII}}$ \\
\cline { 2 - 9 } & $\mathrm{pc}$ & $\mathrm{B}$ & $\mathrm{B}$ & $\mathrm{A}$ & $\mathrm{A}$ & $\mathrm{A}$ & $\%$ & $\%$ \\
\hline \multirow{5}{*}{1,0} & 1 & 5680 & 5832 & 540 & 675 & 560 & 5,3 & 2,8 \\
\cline { 2 - 9 } & 2 & 5393,64 & 5660,6 & 1046 & 1277 & 1098 & 10,1 & 5,8 \\
\cline { 2 - 9 } & 3 & 5130 & 5495 & 5495 & 1500 & 1840 & 16,10 & 8,4 \\
\cline { 2 - 9 } & 4 & 4894,7 & 5344,6 & 1899 & 2314 & 2073 & 18,4 & 10,9 \\
\hline \multirow{5}{*}{0,5} & 1 & 690 & 5838 & 535 & 668 & 553 & 5,1 & 2,7 \\
\cline { 2 - 9 } & 2 & 3406,1 & 5668,4 & 1035 & 1266 & 1085 & 9,9 & 5,5 \\
\cline { 2 - 8 } & 3 & 5150 & 5520 & 1488 & 1828 & 1599 & 14,1 & 8 \\
\cline { 2 - 8 } & 4 & 4914,09 & 5377,1 & 1881 & 2301 & 2058 & 18,01 & 10,4 \\
\hline \multirow{5}{*}{0,06} & 5880 & 6940 & 343 & 430 & 342 & 1,5 & 1,0 \\
\cline { 2 - 8 } & 2 & 5755,94 & 5869,3 & 664 & 843 & 677 & 4,05 & 2,2 \\
\cline { 2 - 8 } & 3 & 5633 & 5810 & 973 & 1235 & 1006 & 6,1 & 3,2 \\
\cline { 2 - 8 } & 4 & 5516,86 & 5743,1 & 1273 & 1616 & 1325 & 8,05 & 4,3 \\
\hline
\end{tabular}

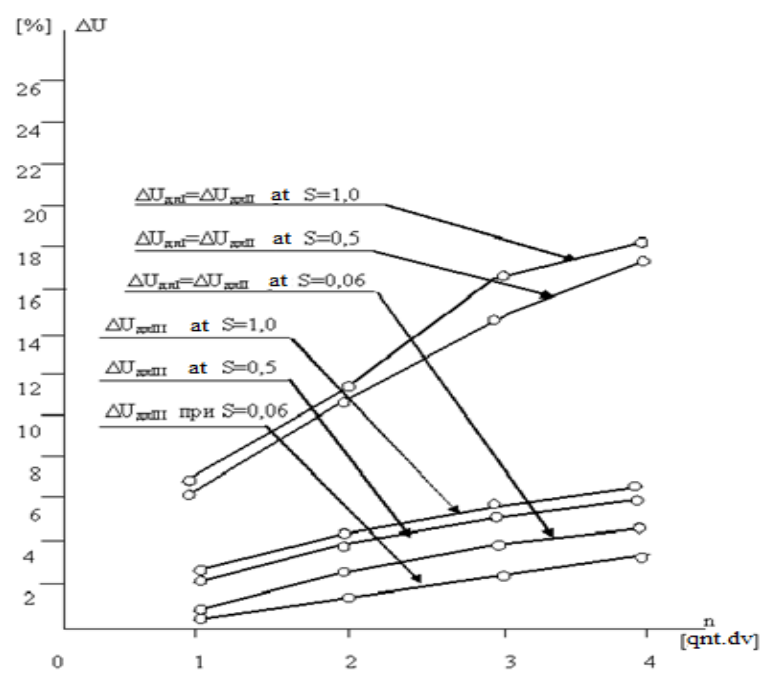

Fig. 3. Number of self-starting pump units

\section{Conclusion}

As a result of the conducted research of pump unit's operation at the first lift pump station it was found out that self-starting of asynchronous motors can be performed. The number of self-starting asynchronous motors at the existing scheme of electric equipment of the pump station depends on the time of short-circuit failure in the network. The maximum number of self-launching induction motors in pumping stations is 8 for a start-up time of $0.8 \mathrm{~s}$ and 4 for a start-up time of 2.5-3 s. The mains voltage drop under these conditions is within the permissible limits. 


\section{References}

1. Khashimov A.A., Khusanov M.A., Abidov K.G. Device for automatic self-starting of pump units. Patent UZ No. IAP 02749 / "Official Gazette", 2005. №3.

2. Khashimov A.A., Abidov K.G. Self-starting of pump units: monograph. -Tashkent: Tashkent State Technical University, 2002. $-112 \mathrm{p}$.

3. Khashimov A.A., Abidov K.G. Energy-efficient methods of self-starting of electric drives of pumping stations (monograph). -Tashkent: "Fan va Technology", 2012. 176 p.

4. Abidov K.G., Sharofutdinov F.H. Method of resourcesaving self-starting of pumping units with an asynchronous electric drive. //Journal "Problems of energy- and resource-saving". ToshDTU-Tashkent, 2016. №1-2. Pages 69-75.

5. Abidov K, Zaripov O.O. Analysis of self-starting modes of pumping motors. -TEST. Engineering and Management, March - April 2020. ISSN: 0193-4120 Page No. 1785 - 1789. (АҚШ).

6. Abidov K, Zaripov O.O. Automatic drive-support method for constant pressure maintanence at pump units of the hydraulic power stations. - E3S.Web of Conferences 216, 01110 (2020) RSES 2020.

7. Abidov, K., Zaripov, O., Zaripova, S. Automatic drive -support method for constant pressure maintanence at pump units of the hydraulic power stations. E3S Web of Conferences, 2020, 216, 01110.

8. Abidov, K., Zaripov, O. Self-starting of pump units when extinguishing voltage in the energy saving mode. E3S Web of Conferences, 2019, 139, 01088. doi: $10.1051 /$ e3sconf $/ 201913901088$

9. Sevinov, J.U., Zaripov, O.O., Zaripova, Sh.O.: The Algorithm of Adaptive Estimation In The Synthesis of The Dynamic Objects Control Systems. Inter. J. of Adv. Science and Techn., 29(5s), 1096-1100 (2020). http://sersc.org/journals/index.php/IJAST/article/vie w/7887.

10. Igamberdiyev, H.Z., Yusupbekov, A.N., Zaripov, O.O., Sevinov, J.U.: Algorithms of adaptive identification of uncertain operated objects in dynamical models. Procedia Computer Science. 120, 854-861 (2017). DOI: 10.1016/j.procs.2017.11.318.

11. Igamberdiev H.Z., Boeva O.H. and Sevinov J.U. Sustainable Algorithms for Selecting Feedback in Dynamic Object Management Systems. Journal of Advanced Research in Dynamical and Control Systems. Volume 12, 07-Special Issue (2020). Pages: 2162-2166.

DOI: 10.5373/JARDCS/V12SP7/20202337.

12. Mallaev A.R., Xusanov S.N., Sevinov J.U. Algorithms of Nonparametric Synthesis of Discrete One-Dimensional Controllers. International Journal of Advanced Science and Technology, Vol 29, № 5s (2020). -PP. 1045-1050.

13. Yusupbekov A.N., Sevinov J.U., Mamirov U.F., Botirov T.V. (2021) Synthesis Algorithms for Neural Network Regulator of Dynamic System Control. In: Aliev R.A., Kacprzyk J., Pedrycz W., Jamshidi M., Babanli M., Sadikoglu F.M. (eds) 14th International
Conference on Theory and Application of Fuzzy Systems and Soft Computing - ICAFS-2020. ICAFS 2020. Advances in Intelligent Systems and Computing, vol 1306. Springer, Cham. https://doi.org/10.1007/978-3-030-64058-3_90.

14. Yusupbekov N.R., Igamberdiev H.Z., Zaripov O.O., Mamirov U.F. (2021) Stable Iterative Neural Network Training Algorithms Based on the Extreme Method. In: Aliev R.A., Kacprzyk J., Pedrycz W., Jamshidi M., Babanli M., Sadikoglu F.M. (eds) 14th International Conference on Theory and Application of Fuzzy Systems and Soft Computing - ICAFS-2020. ICAFS 2020. Advances in Intelligent Systems and Computing, vol 1306. Springer, Cham. https://doi.org/10.1007/978-3-030-64058-3_30. 